\title{
CANOPY STRUCTURE AND DEPOSITION EFFICIENCY OF VINEYARD SPRAYERS
}

\author{
Gianfranco Pergher, Raffaela Petris
}

\section{Introduction}

The use of plant protection products (PPP) in agriculture is a major source of environmental pollution. This is particularly true for PPP used for pest control in orchards and vineyards, owing both to the high number of applications that are required per year, and to the large drift losses associated with broadcast spraying [13]. To reduce the hazards and risks to human health and the environment, a sustainable use of pesticides should aim both at the improvement of application equipment and techniques, and at developing methods to adjust PPP application rates to the actual needs of the crops, while ensuring necessary crop protection and economical viability of agricultural farms [4].

Recent research work suggests that average PPP doses may be reduced by $15 \%$ to $50 \%$, by adjusting the spray volumes according to canopy size, leaf area density and growth stage of the crop. Several methods such as the Tree-Row-Volume [14], Unit Canopy Row [9], and PACE [6], have been developed and tested mostly in fruit orchards. In the case of vineyards, application of such methods is being investigated [8], but is made difficult, on one hand, by the wide variety of training systems, plantation distances, growing techniques and canopies existing in our Country, and, on the other hand, by still insufficient knowledge of the relationship between canopy structure and deposition efficiency of vineyard sprayers.

Experimental evidence shows, however, that foliar deposits tend to decrease when the leaf area index (LAI) of the crop increases, if the same spray volume rate is used [15]. Comparatively large deposits in vine

Paper received 12.07.2006; accepted 14.10.2006

Prof. Gianfranco Pergher, Associate Professor (pergher@ uniud.it), Dr. RAFFAEla PETRIs, PhD student (raffaela.petris@uniud.it). Department of Agricultural and Environmental Sciences (DISA), University of Udine, Italy.

This research was funded by the Italian Ministry of University and Research, MIUR (Project. No. 2003072758, "Reducing pollution from agrochemicals in fruit crops)". canopies have been associated with a low number of leaf layers (1.5) and a certain amount of gaps in the foliage (15\%) [2]. Therefore, the application of a same spray volume results in higher deposits in vineyards with low leaf density area and at the earlier growth stages; however, this also increases the risks associated with higher spray drift [2] and possible fitotoxicity. On the other hand, deposition may be too low to ensure sufficient biological control in the case of large canopies with high leaf density area [6].

The objective of the present research work was to contribute to a better understanding of the relationship between morphological parameters of vine canopies and spray deposition from an air-carrier sprayer.

\section{Materials and methods}

The field tests were performed at the Experimental Station "Servadei", University of Udine, located in S. Osvaldo (UD). The vineyard included three adjoining plots, with vines (cv: Sauvignon Blanc) trained to the Casarsa, High spur cordon and Low spur cordon systems, respectively. Inside each plot, a sample row and 10 sample vines were chosen. Sample rows were separated by approx. $60 \mathrm{~m}$ from each other.

The Casarsa system is typical of Friuli and Veneto, but is also well known elsewhere in Italy. The permanent cordon was trained at $1.2 \mathrm{~m}$ height, and carried four canes per vine, pruned to eight buds each. Planting distances were $2.5 \mathrm{~m}$ between the rows, and $3.0 \mathrm{~m}$ between the posts, with two vines on the opposite sides of each post. The canes were left free to bend downwards during the season, with increasing weight of foliage and grapes. The shoots were also left free, but in part would grow upright and cling to a couple of foliage wires, placed at $1.5 \mathrm{~m}$ and $1.8 \mathrm{~m}$ height, respectively.

The High spur cordon (also known as Single Curtain, or Free Cordon) was trained at $1.45 \mathrm{~m}$ height, and pruned to eight spurs per vine, with two buds each. No foliage wires were present, and vegetation tended to bend down towards the ground in a "curtain" fashion. Planting distances were $2.5 \mathrm{~m}$ between 
the rows, and $1.0 \mathrm{~m}$ between the vines.

The Low spur cordon was trained at $0.8 \mathrm{~m}$ height, and pruned to eight spurs per vine, with two buds each. The shoots were grown upright, and vertically positioned using a couple of mobile wires placed at $1.2 \mathrm{~m}$ height. An additional supporting wire was placed at $1.8 \mathrm{~m}$ height. Planting distances were the same as for the High cordon.

For all training systems, standard canopy management operations were performed, including side and top trimmings, and the removal of shoots arising from below the cordon. Vertical shoot positioning was performed for the Low cordon only; while leaf removal in the grape zone was not performed since it is not recommended for Sauvignon Blanc.

The sprayer was a trailed, air-carrier model (Friuli Ecologic 2000 T 800, Agricolmeccanica, Figure 1), fitted with an axial-flow fan (output: $4.30 \mathrm{~m}^{3} / \mathrm{s}$ ), and a fishtail air conveyor with side outlets. The air speed at $1.25 \mathrm{~m}$ from the fan's centre (equal to half the row distance of the vines) was measured using a HHF23 anemometer (Omega Engineering, Inc.), averaging $7.6 \mathrm{~m} / \mathrm{s}$ in the $0.5 \mathrm{~m}$ to $2.5 \mathrm{~m}$ height range; minimum and maximum speeds were recorded at $0.5 \mathrm{~m}$ and 2.5 $\mathrm{m}$ height, $10.9 \mathrm{~m} / \mathrm{s}$ and $4.4 \mathrm{~m} / \mathrm{s}$ respectively.

Two vertical booms, each fitted with 6 Albuz ATR yellow nozzles (orifice diameter: $1.2 \mathrm{~mm}$ ), were placed near the conveyor's side outlets. The jet holders (Braglia) could be rotated to change the nozzle inclination by $\pm 15^{\circ}$, without affecting the spray output.

Two field tests were performed, at beginning of flowering (stage 17 of Eichorn e Lorenz [7]), and at full foliage development (beginning of berry touch, stage 33).

\subsection{Canopy assessment}

The day before each field test, Point Quadrat measurements were performed on each of the 5 sample vines previously chosen [2], using a $2.4 \mathrm{~m} \times 1.0 \mathrm{~m}$ (height $\times$ width) vertical frame containing a $0.2 \mathrm{~m} \times$ $0.2 \mathrm{~m}$ grid. After placing the frame parallel to the row, a metal rod was introduced horizontally across the

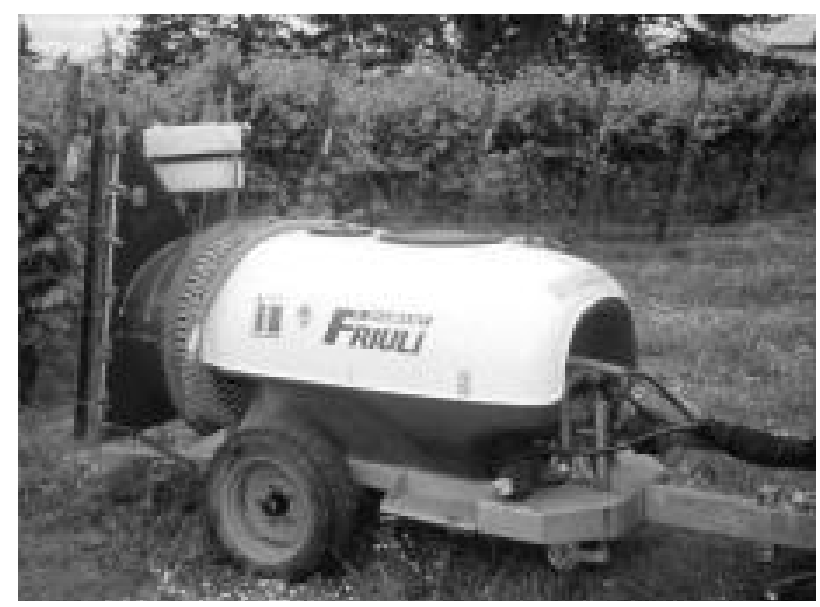

Fig. 1 - The sprayer canopy, and the number of leaves and bunches met by the rod was recorded. This was repeated for each cell of the grid in the height range of $0.6 \mathrm{~m}$ to $2.4 \mathrm{~m}$, giving 60 total measurements per vine. The following canopy parameters were then calculated:

- the number of leaf layers, or the average number of leaves found per each insertion of the rod;

- the percentage of outer leaves and outer bunches, not covered by any other leaf or bunch on at least one side;

- the percentage of canopy gaps, or positions where neither leaves or bunches were met.

\subsection{First test}

At beginning of flowering (5 June 2004), the size of the canopy was distinctly different depending on the training system (Figure 2).

Each sample row was sprayed with one pass on each side, using the nozzles on the right-hand side of the sprayer only. Before that, the number of open nozzles and their directions had been adjusted in the field, following visual assessment of the droplet trajectories [10]. This involved (i) pointing each nozzle in the direction of the air flow (using a plastic tape, $0.5 \mathrm{~m}$ long, to make it visible); (ii) closing those nozzles that did not intercept the canopy; and (iii) turning each nozzle by $\pm 15^{\circ}$, when necessary to better adjust the spray cloud to the canopy.

This resulted in two open nozzles on the right-hand side of the sprayer for both the High and Low cordons, while four open nozzles were used for the Casarsa vines; this was necessary to intercept the bottom portion of the canopy as well, which, on the other hand, had little foliage since most canes were still upright, and just one or two canes per vine were already bent downwards (Figure 2).

During spray application, air temperature was $20.4^{\circ} \mathrm{C}$ to $20.9^{\circ} \mathrm{C}$, relative humidity was $54 \%$ to $59 \%$, and wind speed was 0.4 to $1.3 \mathrm{~m} / \mathrm{s}$. The spray mixture contained $8.8 \mathrm{~g} / \mathrm{l}$ of a food dye tracer (Tartrazin, Cardona), and $17.5 \mathrm{~g} / 1$ of a fungicide (Siaram 20, Siapa), used to retain the physical properties of the adjuvants, and especially of the surfactants, included in commercial formulations of most pesticides.

Nozzle output was assessed using graduated cylinders connected to the nozzles by flexible pipes, at 10 bar pressure. Total output was $2.02 \mathrm{l} / \mathrm{min}$ (High cordon), $2.11 \mathrm{l} / \mathrm{min}$ (Low cordon), or $4.09 \mathrm{l} / \mathrm{min}$ (Casarsa). The spray volumes, at $6.42 \mathrm{~km} / \mathrm{h}$ forward speed, and assuming a working width of $1.25 \mathrm{~m}$ (equal to half the row distance), were $151 \mathrm{l} / \mathrm{ha}, 158$ 1/ha and $3061 /$ ha respectively.

After spraying, three sample leaves were taken from each of 12 canopy locations, resulting from three height ranges $(\mathrm{H} 1, \mathrm{H} 2, \mathrm{H} 3)$ and four depth ranges across the canopy (A, B, C, D) (Figure 2), totalling 36 leaves per sample vine and 540 for the whole experiment. Each sample leaf was placed in a Petri dish. 
The day after, deionised water $(100 \mathrm{ml})$ was added to each Petri dish; leaves were gently stirred with tweezers, turned after $1 \mathrm{~h}$ to wash the other side, stirred again and allowed to stand for another $1 \mathrm{~h}$. A 5 $\mathrm{ml}$ sample of the washing solution was taken, filtered through a $0.22 \mu \mathrm{m}$ microfilter (Millex-GS, Millipore), and optical absorbance on the wavelength $425 \mathrm{~nm}$ was measured with a spectrophotometer (Uvikon 930, Kontron Instruments; resolution: 0.0001; error: \pm $0.002)$. Tracer concentration was determined based on a standard calibration curve. The leaves were finally dried and their area measured with an area-meter (LI3100C, LI-COR Inc.).

On the same day, the leaves remaining on each sample vine were counted; one leaf every 10 was taken, placed in a plastic bag and classified according to its canopy location as defined above (Figure 2). The area of each of these leaves was measured as well.

\subsection{Second test}

At full foliage stage (17 July 2004), the height range of the canopies was relatively similar for all training systems (Figure 2), but their structure was still different.

In the High spur cordon system, most shoots and canes were bending downwards, covering most of the grapes. The canopy was relatively more developed on the south side (left in Figure 2), owing to northern dominant winds in the area; this is common for sprawl canopies without foliage wires. Fruit bearing canes were completely bent downwards in the Casarsa trained vines as well. In all cases, side trimming had been performed at $0.6 \mathrm{~m}$ (High cordon and Casarsa) or at $0.4 \mathrm{~m}$ (Low cordon) from the row.

Sprayer calibration with the above described field method resulted in all 6 nozzles open for the High cordon and Casarsa systems, and in 4 open nozzles

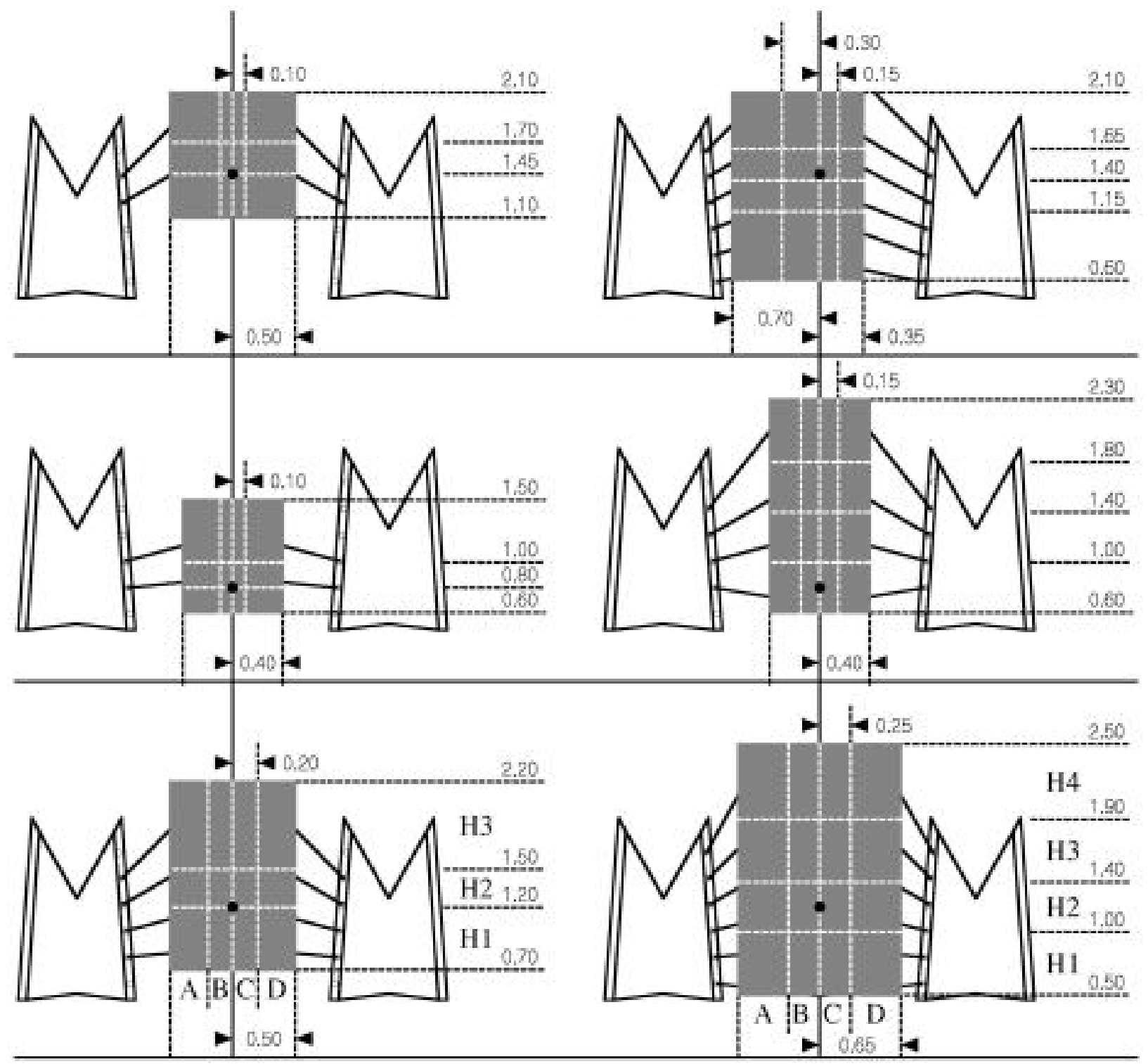

Fig. 2 - Canopy dimensions, sampling zones and nozzle arrangement. On the left: first test: on the right: second test. From the top to the bottom: High Cordon, Low Cordon and Casarsa systems. A, B, C, D: depth zones; H1, H2, H3, H4: height zones. Measures are in m. 
for the Low cordon (Figure 2). The use of 6 open nozzles was not the best possible choice for the High cordon, owing to the asymmetry in the canopy that would have required a different nozzle setting for each side of the row (Figure 2); this was, however, avoided as it was considered unrealistic under normal field conditions.

The test was performed like the previous one, except for the following. The spray mixture contained $11.2 \mathrm{~g} / 1$ Tartrazin and $22.4 \mathrm{~g} / 1$ fungicide. Air temperature was $19.5^{\circ} \mathrm{C}$ to $23.4^{\circ} \mathrm{C}$ during spray application, with relative humidity of $75 \%$ to $87 \%$, and wind speed between 0.3 to $1.2 \mathrm{~m} / \mathrm{s}$. Nozzle output was $4.18 \mathrm{l} / \mathrm{min}$ (Low cordon) or $6.08 \mathrm{l} / \mathrm{min}$ (both High cordon and Casarsa), while the spray volumes, at $6.42 \mathrm{~km} / \mathrm{h}$ forward speed, were 313 l/ha and $455 \mathrm{l} / \mathrm{ha}$, respectively.

Sample leaves were taken from 16 canopy locations, resulting from four height zones and four depth zones. From each locations, two leaves were taken, or 32 leaves per sample vine and 480 leaves for the whole experiment. From each vine, eight sample bunches were also collected, placed each in a plastic bag, and weighed.

To remove the tracer dye, $100 \mathrm{ml}$ deionised water was added to each bag, which was then inflated and shaken vigorously for $30 \mathrm{~s}$. The washing solution was filtered, and optical absorbance was measured as described above.

\subsection{Calculations and statistical analysis}

Based on the number of leaves per vine and their mean area, the partial leaf areas $\left(S_{i}\right.$, in $\left.\mathrm{m}^{2}\right)$ in each sampling location $i$ (height and depth zone), and the total leaf area $\left(S\right.$, in $\left.\mathrm{m}^{2}\right)$ were determined. For each vine, the leaf area index $(L A I)$ and the leaf layer index $(L L I)$ were calculated as:

$$
L A I=S /(x l) \text { and } L L I=S /(x \Delta h)
$$

where: $x$, in $\mathrm{m}$, is the vine length in the row direction; $l$, in $\mathrm{m}$, is the row distance; $\Delta h$, in $\mathrm{m}$, is the height range of the canopy.

Tracer deposits per unit leaf area $\left(d\right.$, in $\left.\mu \mathrm{g} / \mathrm{cm}^{2}\right)$ were determined for each sample leaf as:

$$
d=1000\left(w C_{i}\right) /(2 S)
$$

where $w$, in $\mathrm{ml}$, is the amount of water used to remove the tracer; $C_{i}$, in $\mu \mathrm{g} / \mathrm{ml}$, is the tracer concentration in the washing solution from sample leaf $i$; and $2 S$, in $\mathrm{cm}^{2}$, is double the leaf area.

Deposits on bunches were calculated in the same way, but expressed in $\mu \mathrm{g} / \mathrm{g}$ fresh weight.

For each sample vine, the mean foliar deposit $\left(d_{m}\right.$, $\mu \mathrm{g} / \mathrm{cm}^{2}$ ) was then calculated as the weighed mean of deposits recorded at the various sampling locations, using partial leaf areas $\left(S_{i}\right)$ as weights.

Since tracer application rates were not the same for each of the various treatments (training systems and/ or growth stages), these deposits were, however, not directly comparable. Therefore, they were normalised assuming a fixed tracer application rate:

a) per open nozzle:
$d_{n}(U)=d n T^{\prime} / T_{E}$

b) per unit height of the canopy:

$d_{n}(H)=d T_{N}{ }_{N} \Delta h / T_{E}$

c) per unit ground surface:

$d_{n}(S)=d T_{S} / T_{E}$

where: $d_{n}$ is the normalised deposit; $d$, in $\mu \mathrm{g} / \mathrm{cm}^{2}$ or $\mu \mathrm{g} / \mathrm{g}$, is the actual deposit; $n$ is the number of nozzles open; $T_{E}$, in $\mathrm{g} / \mathrm{ha}$, is the tracer application rate per unit ground surface; $T^{\prime}{ }_{U}, T^{\prime}{ }_{N}$ and $T^{\prime}{ }_{S}$ are the amounts of tracer applied in the Casarsa plots at beginning of flowering, which were arbitrarily assumed as "normal" application rates, viz. $673 \mathrm{~g} /$ ha per open nozzle, $1795 \mathrm{~g} / \mathrm{ha} / \mathrm{m}$ canopy height, and $2693 \mathrm{~g} / \mathrm{ha}$.

As an example, for High spur cordon in the first stage, $n=2 ; d=2.93 \mu \mathrm{g} / \mathrm{cm}^{2} ; T_{E}=1329 \mathrm{~g} / \mathrm{ha} ;$ and $\Delta h$ $=1 \mathrm{~m}$. Tracer application rates were: $T^{\prime}{ }_{U}=673 \mathrm{~g} / \mathrm{ha}$; $T^{\prime}{ }_{N}=1795 \mathrm{~g} / \mathrm{ha} / \mathrm{m} ; T^{\prime}{ }_{S}=2693 \mathrm{~g} / \mathrm{ha}$. Therefore, the normalised deposits were:

$d_{n}(U)=2.93 \cdot 2 \cdot 673 / 1329=2.97\left[\mu \mathrm{g} / \mathrm{cm}^{2}\right]$
$d_{n}(H)=2.93 \cdot 1795 \cdot 1 / 1329=3.96\left[\mu \mathrm{g} / \mathrm{cm}^{2}\right]$
and $d_{n}(S)=2.93 \cdot 2693 / 1329=5.94\left[\mu \mathrm{g} / \mathrm{cm}^{2}\right]$.

Total foliar deposition ( $D, \%$ of total dose) was finally determined for each sample vine as:

$$
D=10000\left(2 d_{m} L A I\right) /\left(C_{T} V\right)
$$

where $C_{T}$, in $\mathrm{g} / \mathrm{l}$, is the tracer concentration in the spray mixture, and $V$, in $1 /$ ha, is the spray volume.

Analysis of variance was used for statistical analysis, following a randomised-block design with three treatments (High cordon, Low cordon, and Casarsa) and five replicates, although formal randomisation had not been possible. The Student-Newman-Keuls test was used for mean comparison.

\section{Results and discussion}

\subsection{Canopy morphology}

At beginning of flowering, the leaf area index was similar (0.93 to 1.29 ; Table 1$)$ for all different training systems. Between beginning of flowering and berry touch stages, the leaf area index (LAI) increased noticeably in all cases (1.70 to 3.76); in the same time, the number of leaf layers also increased (excepting the Low spur cordon), while the percentage of outer leaves and the gaps in the canopy decreased.

It can be observed that the number of leaf layers from the point Quadrat method was always lower than the leaf layer index $(L L I)$. In fact, it can be shown [12] that the latter would equal the former only assuming that all leaves were placed vertically and parallel to the row, which was obviously not the case. However, the difference between P.Q. leaf layers and $L L I$ could be used as an index of leaf inclination, relative to the vertical plane passing through the row.

The increase in the leaf area index was related to an increase both in canopy height and in the mean number of leaf layers. However, some differences between the three training system can be observed. In the High cordon, the leaf area index increased nearly 


\begin{tabular}{|c|c|c|c|c|c|c|c|c|}
\hline Growth stage & $\begin{array}{l}\text { Training } \\
\text { system }\end{array}$ & $\begin{array}{l}\text { Height } \\
\text { range } \\
(\mathrm{m})\end{array}$ & $\begin{array}{c}\text { Leaf area } \\
\text { index } \\
\text { (LAI) }\end{array}$ & $\begin{array}{l}\text { Leaf } \\
\text { layer } \\
\text { index } \\
\text { (LLI) }\end{array}$ & $\begin{array}{c}\text { Leaf } \\
\text { layers } \\
\text { (Point } \\
\text { Quadrat) }\end{array}$ & $\begin{array}{c}\text { Outer } \\
\text { leaves } \\
(\%)\end{array}$ & $\begin{array}{c}\text { Outer } \\
\text { bunches } \\
(\%)\end{array}$ & $\begin{array}{c}\text { Gaps } \\
(\%)\end{array}$ \\
\hline \multirow{3}{*}{ Beginning of flowering } & High cordon & $1.1-2.1$ & 1.29 & 3.22 & 2.02 & 67 & - & 27 \\
\hline & Low cordon & $0.5-1.5$ & 0.93 & 2.59 & 2.15 & 68 & - & 20 \\
\hline & Casarsa & $0.7-2.2$ & 1.16 & 1.98 & 1.32 & 71 & - & 46 \\
\hline \multirow{3}{*}{$\begin{array}{l}\text { Beginning of berry } \\
\text { touch (whole canopy) }\end{array}$} & High cordon & $0.6-2.1$ & 3.37 & 5.62 & 3.94 & 34 & - & 21 \\
\hline & Low cordon & $0.6-2.3$ & 1.7 & 2.49 & 2.16 & 61 & - & 23 \\
\hline & Casarsa & $0.5-2.5$ & 3.76 & 4.69 & 3.35 & 38 & - & 19 \\
\hline \multirow{3}{*}{$\begin{array}{l}\text { Beginning of berry } \\
\text { touch (grape zone) }\end{array}$} & High cordon & $1.2-1.6$ & - & 10.82 & 7.36 & 24 & 9 & 0 \\
\hline & Low cordon & $0.6-1.0$ & - & 2.85 & 2.81 & 43 & 33 & 2 \\
\hline & Casarsa & $0.9-1.4$ & - & 7.02 & 4.65 & 28 & 32 & 0 \\
\hline
\end{tabular}

TABLE 1 - Canopy assessment.

2.6 times, owing both to an increase in canopy height $(+50 \%)$ and in the mean number of leaf layers (Point Quadrat; +95\%; Table 1). In the Casarsa system, the canopy developed more in width (leaf layers: $+223 \%$ ) than in height (from $1.5 \mathrm{~m}$ to $2.0 \mathrm{~m} ;+33 \%$ ). In the Low cordon, the LAI at the second stage was significantly lower (1.70 versus 3.37 and 3.76, High cordon and Casarsa, respectively); the canopy developed only in height $(+89 \%)$, while the number of leaf layers was nearly the same at both growth stages.

The high percentage of gaps in the Casarsa canopy at beginning of flowering (46\%) should be noticed, and will be discussed later. Gaps were mainly located below the permanent cordon (height zone $1,80 \%$ of gaps).

In all training systems, the grape zone was concentrated in height $(0.4$ to $0.5 \mathrm{~m})$, with no gaps and more leaf layers than in the remaining portions of the canopy; this was particularly true for the High cordon (7.36 layers) and the Casarsa (4.65 layers). The bunches were mainly located in the inside of the canopy, particularly in the High cordon (only $9 \%$ of outer bunches).

\subsection{Foliar deposits}

The mean foliar deposits are reported in Table 2. It should be noted that, for Casarsa at beginning of flowering, deposits were the same independently of the normalisation applied, since this condition had been used as a reference case.

The three normalisation methods used in this study reflect as many different criteria for adjusting the pesticide dose to different canopies. Criterion (a), fixed dose per open nozzle, reflects the empirical method, used in the present field tests and often applied by the growers in their field practice, consisting in just switching off those nozzles that do not intercept the canopy, following visual assessment. This results in a volume rate that is roughly proportional to the canopy height; as a consequence, pesticide dose rate is changed accordingly, if pesticide concentration is kept constant. In other words, the tracer deposits calculated with normalisation criterion (a) (Table 2) are proportional to the pesticide deposits that could be obtained using the above empirical method.

These deposits were in the range of 3.92 to 4.44

\begin{tabular}{|c|c|c|c|c|c|c|}
\hline & \multicolumn{3}{|c|}{ Beginning of flowering } & \multicolumn{3}{|c|}{ Beginning of berry touch } \\
\hline & $\begin{array}{l}\text { High spur } \\
\text { cordon }\end{array}$ & $\begin{array}{l}\text { Low spur } \\
\text { cordon }\end{array}$ & Casarsa & $\begin{array}{l}\text { High spur } \\
\text { cordon }\end{array}$ & $\begin{array}{l}\text { Low spur } \\
\text { cordon }\end{array}$ & Casarsa \\
\hline \multicolumn{7}{|l|}{$\begin{array}{l}\text { Mean weighed foliar deposit }\left(\mu \mathrm{g} / \mathrm{cm}^{2}\right) \text {, } \\
\text { normalised assuming: }\end{array}$} \\
\hline (a) a fixed dose per open nozzle & $2.97 \mathrm{~b}$ & $3.97 \mathrm{a}$ & $3.92 \mathrm{a}$ & $4.38 \mathrm{a}$ & $3.89 \mathrm{a}$ & $4.44 \mathrm{a}$ \\
\hline (b) a fixed dose per unit canopy height & $3.96 \mathrm{a}$ & $4.77 \mathrm{a}$ & $3.92 \mathrm{a}$ & $2.92 \mathrm{~b}$ & $4.41 \mathrm{a}$ & $3.95 \mathrm{a}$ \\
\hline (c) a fixed dose per unit ground area & $5.94 \mathrm{~b}$ & $7.94 \mathrm{a}$ & $3.92 \mathrm{c}$ & $2.92 \mathrm{c}$ & $3.89 \mathrm{c}$ & $2.96 \mathrm{c}$ \\
\hline Total foliar deposition on the canopy $(\%)$ & $57.1 \mathrm{~b}$ & $55.3 \mathrm{~b}$ & $33.6 \mathrm{c}$ & $73.3 \mathrm{a}$ & $48.6 \mathrm{~b}$ & $82.3 \mathrm{a}$ \\
\hline C.V. of deposits between single leaves (\%) & 54 & 46 & 49 & 44 & 41 & 49 \\
\hline
\end{tabular}

Means on the same line with the same letter are not significantly different at $p=0.05$ (Student - Newman - Keuls test).

TABle 2 - Mean foliar deposits. 


\begin{tabular}{lcccccc}
\hline & $\begin{array}{c}\text { Leaf area index } \\
\text { (LAI) }\end{array}$ & $\begin{array}{c}\text { Leaf layer index } \\
\text { (LLI) }\end{array}$ & $\begin{array}{c}\text { Leaf layers } \\
\text { (Point } \\
\text { Quadrat) }\end{array}$ & $\begin{array}{c}\text { Outer leaves } \\
(\%)\end{array}$ & $\begin{array}{c}\text { Outer } \\
\text { bunches } \\
(\%)\end{array}$ & $\begin{array}{c}\text { Gaps } \\
(\%)\end{array}$ \\
\hline $\begin{array}{l}\text { Total foliar deposition }(\%) \\
\text { Normalised foliar deposit: }\end{array}$ & $0.79 * * *$ & $0.84 * * *$ & $0.77 * * *$ & $-0.43 *$ & - & $-0.49 * *$ \\
(a) fixed dose per open & $0.43 *$ & $0.28 \mathrm{~ns}$ & $0.35 \mathrm{~ns}$ & $-0.07 \mathrm{~ns}$ & - & $-0.11 \mathrm{~ns}$ \\
(b) fixed dose per unit & $-0.52 * *$ & $-0.59 * * *$ & $-0.54 * *$ & $0.58 * * *$ & - & $-0.05 \mathrm{~ns}$ \\
(c) fixed dose per unit & $-0.70 * * *$ & $-0.47 * *$ & $-0.47 * *$ & $0.57 * *$ & - & $-0.08 \mathrm{~ns}$ \\
Normalised bunch deposit: & & & & & & \\
(a) fixed dose per open & - & $-0.60 *$ & $-0.43 \mathrm{~ns}$ & $0.55 *$ & $0.04 \mathrm{~ns}$ & $0.23 \mathrm{~ns}$ \\
(b) fixed dose per unit & - & $-0.79 * * *$ & $-0.63 *$ & $0.71 * *$ & $0.20 \mathrm{~ns}$ & $0.31 \mathrm{~ns}$ \\
(c) fixed dose per unit & - & $-0.74 * *$ & $-0.57 *$ & $0.70 * *$ & $0.12 \mathrm{~ns}$ & $0.31 \mathrm{~ns}$ \\
\hline
\end{tabular}

TABLE 3 - Correlation coefficient (r) for deposits and morphological parameters. Significant statistical values for $\mathrm{p}<0.001(* * *)$, $\mathrm{p}<0.01(* *), \mathrm{p}<0.05(*)$, or not significant (ns) are shown.

$\mu \mathrm{g} / \mathrm{cm}^{2}$ (Table 2; excepting the High cordon at stage 1 , discussed below), and were not noticeably affected by either the training system or the growth stage. Correlation of deposits versus the morphological parameters of the canopy (Table 3) was generally not significant, which is consistent with the above observation.

However, a significantly lower deposit was recorded for the High cordon at beginning of flowering $\left(2.97 \mu \mathrm{g} / \mathrm{cm}^{2}\right.$; Table 2). This may be owing to the fact that the empirical method was subjective and approximate by definition, and adjustments were possible only in finite steps: very probably, using something between 2 and 3 nozzles for the High cordon at the first stage would have yielded mean deposits comparable to those recorded in the other five cases.

Normalisation criterion (b), fixed dose per unit canopy height, reflects a simple adjustment method suggested by some Authors [8]. This implies that the nozzle output and/or the pesticide concentration must be adjusted to obtain an application rate proportional to the height of the canopy. Even in this case, comparable deposits were recorded in five of six cases (3.92 to 4.77 $\mu \mathrm{g} / \mathrm{cm}^{2}$; Table 2), with the exception of High cordon at full foliage, significantly lower $\left(2.92 \mu \mathrm{g} / \mathrm{cm}^{2}\right)$.

These deposits were significantly correlated with most morphological parameters of the canopy (Table $3)$. More particularly, deposits decreased for an increase in the leaf area index, the leaf layer index and the leaf layers (Point Quadrat), and increased with the percentage of outer leaves, as observed by other Authors $\left[^{2}\right]$. On the other hand, the mean deposits were not significantly affected by the percentage of gaps in the canopy.

Significant correlation of deposits versus $L L I$ $(r=-0.59)$ and outer leaves $(r=+0.58)$ probably reflected the comparably lower deposition observed on the High cordon at full foliage stage ( $L L I=5.62$; outer leaves: $34 \%$ ). This seems to imply that a dose rate adjustment proportional to canopy height may not be recommendable for canopies with $L L I>5$.

Normalisation criterion (c), fixed dose per ground surface, implies that pesticide application rate is kept constant, independently of the training system and the growth stage. The resulting deposits varied in a rather broad range (2.92 to $7.94 \mu \mathrm{g} / \mathrm{cm}^{2}$; Table 2$)$, and were significantly higher for both spur cordons at beginning of flowering. Correlation between these deposits and morphological parameters was similar to what has been observed for deposit normalisation (b) (Table 3).

Coefficients of variation (C.V.) of mean deposits recorded in the six cases considered in this study were $13 \%, 16 \%$, and $43 \%$ for methods (a), (b), and (c), respectively. This shows that methods (a) and (b) for dose rate adjustment may substantially reduce deposit variability, owing to different canopy structures, relative to method (c).

These conclusions may not be true if dose rate adjustments are carried out merely by adjusting the spray volume rate; in fact, excessive volume rates may increase losses to the ground and reduce deposition over the canopy. They are probably true, on the other hand, if doses are adjusted by changing the pesticide concentration in the spray mixture, and particularly for low volume applications. In fact, recent research showed that deposition efficiency of vineyard sprayers was not affected by volume rates below 200 1/ha per $m$ height of the canopy [1].

Variability of deposits inside each sample vine will not be discussed in this paper because of brevity. However, coefficients of variations (C.V. of deposits between single sample leaves (Table 2), or between sampling locations were comparably the same as in previous studies $[12,13,15]$.

\subsection{Total foliar deposition}

Total foliar deposition on the canopy (\% of volume applied) was generally lower at beginning of flowering than at full foliage stage (Table 2). Significantly lower deposition was recorded for Casarsa at the first growth stage $(33.6 \%)$, while significantly higher at the second stage for the High Cordon $(73.3 \%)$ and Casarsa $(82.3 \%)$.

Total foliar deposition was significantly correlated 


\begin{tabular}{lccc}
\hline $\begin{array}{l}\text { Mean normalised } \\
\text { bunch deposit: }\end{array}$ & $\begin{array}{c}\text { High } \\
\text { spur } \\
\text { cordon }\end{array}$ & $\begin{array}{c}\text { Low } \\
\text { spur } \\
\text { cordon }\end{array}$ & Casarsa \\
\hline $\begin{array}{l}\text { (a) fixed dose per open } \\
\text { nozzle } \\
\text { (b) fixed dose per unit } \\
\text { canopy height } \\
\text { (c) fixed dose per unit }\end{array}$ & $4.33 \mathrm{~b}$ & $6.72 \mathrm{a}$ & $3.79 \mathrm{~b}$ \\
$\begin{array}{l}\text { ground area } \\
\text { C.V. of deposits between } \\
\text { single bunches (\%) }\end{array}$ & $2.88 \mathrm{~b}$ & $7.61 \mathrm{a}$ & $3.37 \mathrm{~b}$ \\
\hline $\begin{array}{l}\text { Means on the same line with the same letter are not significantly } \\
\text { different at } p=0.05 \text { (Student-Newman-Keuls test). }\end{array}$ & $6.72 \mathrm{a}$ & $2.53 \mathrm{~b}$ \\
\hline
\end{tabular}

TABLE 4 - Mean deposition on bunches.

with all morphological parameters considered in this study (Table 3); this included the gaps in the canopy $(r=-49 \%)$, consistently with the high percentage of gaps $(46 \%)$ recorded on Casarsa at the first stage.

Deposition was particularly well correlated with the leaf layer index $(L L I)(\mathrm{r}=+0.84$, Table 2$)$. The increase in foliar deposition was nearly proportional for $1.5 \leq L L I \leq 4$, while less than proportional for $4 \leq$ $L L I \leq 7$ approximately (Figure 3). Comparatively low deposition in High cordon, even at high $L L I$, might be owing to the difficulty of adjusting the nozzle direction for an asymmetrical canopy at full foliage stage; in fact, as already observed, average total deposition was just $73.2 \%$, versus $82.3 \%$ in Casarsa, despite higher average $L L I$ (5.62 versus 4.69).

\subsection{Deposition on bunches}

Mean deposits on bunches were generally higher in the Low spur cordon, relatively to both the High cordon and the Casarsa system, independently of the normalisation criterion used (Table 4). In the Low cordon, deposits were, in addition, much less variable, as indicated by the lower coefficient of variation (C.V.)

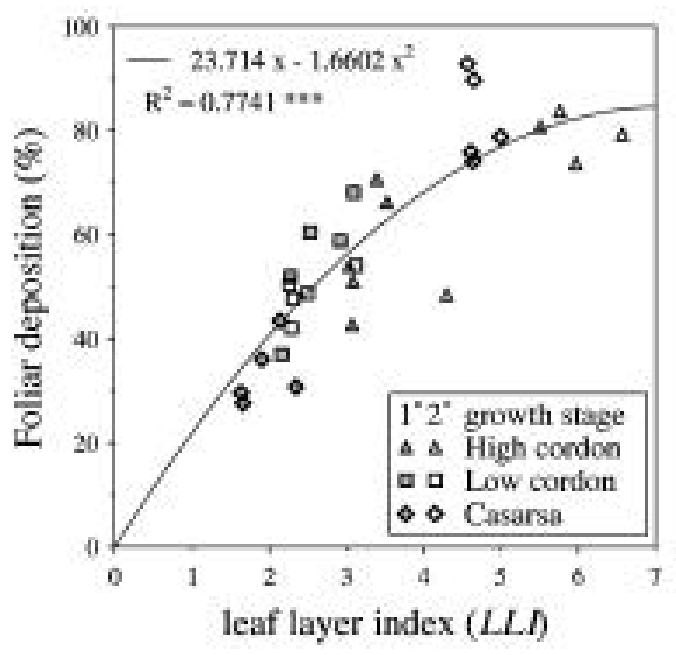

Fig. 3 - Total foliar deposition ( $\%$ of volume applied) versus leaf layer index.

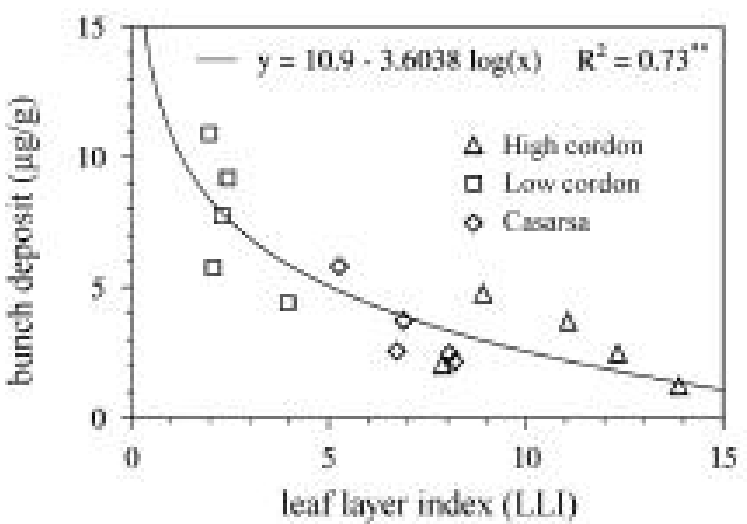

Fig. 4 - Bunch deposits, normalised assuming a constant dose per unit canopy height, versus leaf layer index in the bunch zone.

between single sample bunches.

This was significantly related to the leaf layer in$\operatorname{dex}(r=-0.79$; using normalisation criterion (b), fixed dose per unit canopy height), Point Quadrat leaf layers $(r=-0.63)$, and percentage of outer leaves $(r=$ +0.71 ) (Table 3; all parameters referring to the grape zone). The effect of the leaf layer index on bunch deposition is shown in Figure 4.

No significant correlation was found, however, with the percentage of outer bunches or with the gaps in the foliage, both of which were, on the other side, scarcely affected by the training system.

\section{Conclusions}

The results presented show that a dose rate adjustment proportional to the canopy height may reduce deposit variability owing to different training systems and growth stages of the vines. This may be obtained using either the empirical method of closing out-of-target nozzles, or by changing the pesticide concentration and/or nozzle output (e.g. using different nozzle size) in order to maintain a constant dose per unit height of the canopy. The latter method has several practical advantages over the former: it is still simple to use; it is less affected by the user's subjective evaluation; it makes a continuous and more accurate variation of the dose possible. However, the present results suggest the need to define a correction factor to account for very dense canopies, with $L L I>4$ approximately.

The reduction in deposit variability is particularly advantageous if different training systems are present in the same farm; in fact, this may lead to a decrease in the amounts of pesticides applied, particularly for vines with small sized canopies and lower leaf area density. However, obtaining the same level of deposits per unit leaf area over the whole season may not be correct on a biological basis; in fact, the crop's sensitivity to a given disease or pest might be different, depending on the growth stage. In this case, biological evaluation will be needed before practical application of a dose adjustment method. 
The present results suggest, on the other side, that different canopy structures may affect the deposition efficiency of vineyard sprayers as well. From this point of view, an ideal canopy should be symmetrical and uniformly shaped, to avoid the problems found at full foliage stage in the High cordon, and to make sprayer adjustment easier and quicker. The presence of ample gaps in the foliage should be avoided, since it may reduce total canopy deposition as in the Casarsa at beginning of flowering, and increase drift losses. In the grape zone, deposition is increased by a low number of leaf layers, as in the training systems with vertically positioned shoots (Low spur cordon, or Guyot); any management technique able to reduce the leaf layers at grape level will be beneficial under this respect, including shoot thinning, and leaf manual or mechanical removal.

The Low spur cordon includes most of the features of such an "ideal" canopy. However, because of the low number of leaf layers in this training system (2.49 to 2.59 in this study), total foliar deposition is comparably small ( $48.6 \%$ to $57.1 \%)$, even at full foliage stage. This increases the risk of higher drift losses, relative to other training systems with denser canopies, as recorded by previous studies $\left[{ }^{3}\right]$. The problem should not be underestimated because of its implications for human health and the environment. To reduce these risks, a reduction of the air flow rates even below $4 \mathrm{~m}^{3} / \mathrm{s}$, as suggested by recent research $\left[{ }^{1}\right]$, or the use of shielded sprayers, should be recommended.

\section{References}

[1] Balsari P., Pergher G., Ade G., Vieri M., Guarella P., Giametta G., Cerruto E., Come tarare le macchine irroratrici per vigneto. Informatore Agrario (2004), 10, 31-40.

[2] Balsari P., Scienza A., Forme di allevamento della vite e modalità di distribuzione dei fitofarmaci. Bayer CropScience, Milano, 2003.

[3] Balsari P., Marucco P., Influence of canopy parameters on spray drift in vineyard. Aspects of Applied Biology (2004), 71(1), 157-164.

[4] Commission of the European Communities, Towards a thematic strategy on the sustainable use of pesticides. Brussels, 1.7.2002.

[5] CONAMA. Certificato $n^{\circ}$ 05-058a. Irroratrice: Friuli DIA TV 2000. Roma, 1997.

[6] Cross J.V., Walklate P.J., Pesticide dose adjustment to the crop environment (PACE): Adjusting the dose to suit the crop. Proceedings, Spray Application Techniques in Fruit Growing (2003), Cuneo, Italia, 25-27 Giugno 2003, 315-330.

[7] Eichorn K.W., Lorenz D.H., Phaenologische Entwicklungsstadien der Rebe. Nachrichtenbl. Deut. Pflanzenschutzd. (Braunschweig) (1977), 29: 119120.

[8] Franchi A., Barani A., Giosué S., Prime osservazioni sull'impiego del modello di calibratura dello spray UCR e dei dosaggi in applicazioni su Vitis vinifera. Atti Giornate Fitopatologiche (2006), 513520.
[9] Furness G.O., Magarey P.A., Miller P.H., Drew H.J., Fruit tree and vine sprayer calibration based on canopy size and length of row: unit canopy row method. Crop Protection (1998), 17 (8), 639-644.

[10] Kaul P., Koch H., KNewitz H., Schmidt K., Gebauer S., Vorschläge zur Gestaltung der Gebrauchsanleitung von Sprühgeräten im Obstbau. Nachrichtenblatt des Deutschen Pflanzenschutzdienstes (2004), 56 (4), $77-82$.

[11] Pergher G., Recovery Rate of Tracer Dyes Used for Spray Deposit Assessment. Transactions of the ASAE (2001), 44(4), 787-794.

[12] PERGHER G. Field evaluation of a calibration method for air-assisted sprayers involving a vertical patternator. Crop protection (2004), 23:5, 437-446.

[13] Pergher G., Gubiani R., The effect of spray application rate and airflow rate on foliar deposition in a hedgerow vineyard. Journal of agricultural Engineering Research (1995), 61, 205-216.

[14] Steffek R., ReisenZein H., Persen U., Tree-RowVolume, a new way for the registration of plant-protective agents in orchards? Acta Horticulturae (2000), 525, 195-200.

[15] VIERI M., GIORGETTI R., Risultati di prove comparative su due irroratrici ad aeroconvezione (diffusore convenzionale e moduli di irrorazione) con differenti tarature adottate. Atti Giornate Fitopatologiche (2002), Vol. 2, 25-32.

\section{SUMMARY}

A field study was performed to analyse how deposition efficiency from an axial-fan sprayer was affected by the canopy structure of vines trained to the High Cordon, Low Cordon and Casarsa systems, at beginning of flowering and beginning of berry touch growth stages.

An empirical calibration method, providing a dose rate adjustment roughly proportional to canopy height, was used. The canopy structure was assessed using the Point Quadrat method, and determining the leaf area index (LAI) and the leaf layer index (LLI). Spray deposits were measured by colorimetry, using a water soluble dye (Tartrazine) as a tracer.

Correlation between deposits and canopy parameters were analysed and discussed. Foliar deposits per unit leaf area were relatively constant, suggesting that empirical calibration can reduce deposit variability associated with different training systems and growth stages. Total foliar deposition ranged from $33.6 \%$ and $82.3 \%$ of total spray volume, and increased proportionally with the LLI up to $\mathrm{LLI}<4$. Deposits on bunches significantly decreased with the LLI in the grape zone.

The results suggest that sprayer efficiency is improved by a regular, symmetrical canopy, with few leaf layers in the grape zone as in Low Cordon. However, a LLI $<3$ over the whole canopy and $>40 \%$ gaps in the foliage both reduced total deposition, and may increase the risk for larger drift losses.

\section{Key words:}

Canopy structure, Vineyard, Sprayer, Dose rate adjustment. 